\title{
Heparin Induced Thrombocytopenia for the Perioperative and Critical Care Clinician
}

\author{
Ingrid Moreno-Duarte ${ }^{1} \cdot$ Kamrouz Ghadimi $^{1}$ (D) \\ Published online: 29 August 2020 \\ (C) Springer Science+Business Media, LLC, part of Springer Nature 2020
}

\begin{abstract}
Purpose of Review This review will illustrate the importance of heparin-induced thrombocytopenia in the intraoperative and critical care settings.

Recent Findings Heparin-induced thrombocytopenia (HIT) occurs more frequently in surgical patients compared with medical patients due to the inflammatory release of platelet factor 4 and perioperative heparin exposure. Recognition of this disease requires a high index of suspicion. Diagnostic tools and therapeutic strategies have been expanded and refined in recent years. Summary HIT is a condition where antibodies against the heparin/platelet factor 4 complex interact with platelet receptors to promote platelet activation, aggregation, and thrombus formation. Our review will focus on intraoperative and postoperative considerations related to HIT to help the clinician better manage this rare but often devastating hypercoagulable disease process.
\end{abstract}

Keywords Heparin $\cdot$ Thrombocytopenia $\cdot$ Surgery $\cdot$ Limb ischemia $\cdot$ Thrombosis

\section{Introduction}

Heparin-induced thrombocytopenia (HIT) is a prothrombotic disease where antibodies against the molecular complex of heparin-to-platelet factor 4 (PF4/H) interact with platelet receptors to promote platelet activation, aggregation, and removal from circulation $[1,2 \cdot]$. PF4 is secreted by platelet granules or displaced from the endothelium. HIT antibodies against the heparin/PF4 complex will trigger downstream thrombin generation and catastrophic thrombus formation. The prevalence of HIT is rare in both medical and surgical patients, and the incidence in most population-based studies ranges between 0.3 and $3.0 \%$. However, the occurrence of HIT in the operating theater or the postoperative critical care setting can be swift and devastating. In this review, we will discuss standard definitions, scoring systems, epidemiology, and pathogenesis that is relevant to the perioperative and critical care environments. For our review, we will be referring to

This article is part of the Topical Collection on Blood Management

Kamrouz Ghadimi

kamrouz.ghadimi@duke.edu

1 Department of Anesthesiology \& Critical Care, Duke University

School of Medicine, DUMC Box 3094, Durham, NC 27710, USA the type 2 variety of HIT, where an immune-mediated disorder emerges typically 4-10 days after heparin exposure to heparin and has life- and limb-threatening thrombotic complications $[2 \cdot, 3]$. There will be a limited focus on the less clinically important type 1 , which is a non-immune process that presents within the first 2 days after heparin exposure with correction of thrombocytopenia despite continuation of heparin therapy [3].

\section{Definition and Epidemiology}

Approximately $20-50 \%$ of critically ill patients present with thrombocytopenia in the intensive care unit (ICU), whereby a reduced platelet count below 150,000 platelets per microliter of blood is noted on laboratory testing [4]. Heparinoid exposure by syringe flush, subcutaneous prophylaxis, or therapeutic anticoagulation is common in the operative room (OR) and ICU environments [5]. Only a fraction of those with low platelet counts will develop HIT, which presents in approximately $0.3-0.5 \%$ of critically ill patients exposed to heparin [6]. These statistics suggest that around 1 in 100 ICU patients will develop thrombocytopenia due to HIT $[1,4,7]$. HIT is paradoxically linked to a high risk for arterial and venous thromboses. Almost half of the critically ill patients diagnosed with HIT will present with thrombotic events $[5,8]$. 
HIT presents in the setting of higher concentrations of platelet factor 4 (PF4) leading to the formation of PF4/H complexes. Surgery can trigger the release of massive amounts of PF4 [9]. Therefore, the frequency of HIT varies with the type of surgery. Five percent of orthopedic surgical patients exposed to heparin for 10-14 days present with HIT [10-12]. Shorter courses of heparin treatment seem to decrease the risk of HIT development [13]. Preferential use of low molecular weight heparin (LMWH) as opposed to unfractionated heparin (UFH) is associated with lower rates of HIT [14•]. In cardiac surgery patients, the frequency of HIT is approximately $2 \%[15,16 \bullet]$. Although HIT is less frequent in cardiac surgical patients compared with orthopedic patients, cardiac surgical patients have a higher frequency of HIT immunization (positive antibody formation) [15], potentially due to the high intraoperative UFH doses required for anticoagulation on cardiopulmonary bypass [7, 17]. HIT presents in trauma patients with a frequency of around 2.2\% [18]. Patients with major trauma showed higher rates of seroconversion compared with patients with minor trauma (OR 7.98 [95\% CI 2.06-31.00]; $P=0.003)$. In these patients, HIT incidence was lower when using LMWH versus UFH, although the difference was not statistically significant (LMWH $1.3 \%$ vs. UFH $0.3 \% ; P=$ 0.37).

HIT occurs more frequently in surgical patients compared with medical patients [19, 20]. Medical patients present a HIT prevalence of around $0.8-2.0 \%$ [20, 21]. Gender seems to be a risk factor for HIT and females are more affected than men (OR, 9.22 vs. $1.83 ; P=.020$ ) [19]. HIT is uncommon in obstetric patients [22].

The type of heparin used is a well-described risk factor for HIT. A small study with patients undergoing first-time $\mathrm{CABG}$ reported a seroconversion rate of $44.4 \%$ for bovine heparin and $30.6 \%$ for porcine heparin. Intraoperatively, bovine heparin is less frequently used compared with porcine heparin, and in the setting of HIT, both should be avoided [23]. Unfractionated heparin has been significantly associated with a higher incidence of HIT (almost 10fold higher), [2•] compared with LMWH and selective factor Xa inhibitors like fondaparinux [9, 18, 19, 24] likely due to the difference of the polysaccharide chain lengths and the degree of sulfation of each medication [25]. Of importance, dosing seems to be correlated to the risk of developing HIT. Prophylactic UFH is more frequently associated with HIT compared with therapeutic $\mathrm{UFH}$, due to the fluctuations in the $\mathrm{PF} 4 / \mathrm{H}$ ratio. $\mathrm{LMWH}$ and fondaparinux are less likely to form multimolecular complexes with PF4 and, consequently, less likely to induce HIT.

The variability in the reported frequency of HIT is due to the multiple factors. Differences in the studied populations (medical vs. surgical) [15], type of heparin used [9, 24], duration of therapy, [10] and female over-representation [19] have been strongly correlated with such variability. Other limitations of the studies include selection bias, inconsistency in the definitions used for thrombocytopenia and HIT, discrepancy/ inconsistency of tests performed for confirmation, and differences in baseline patient characteristics (including baseline platelet counts, inclusion of patients with early thrombocytopenia, and the failure to exclude patient whose platelet counts recovered during continue heparin treatment) [19, 26-28].

In the ICU, exposure to UFH occurs from flushes and heparin-bonded devices. Although rare, Swan-Ganz catheters and extracorporeal circuits may be heparin coated to avoid thrombus formation during routine standard use. Even minor heparin exposures can elicit the formation of HIT antibodies [29], but not all antibodies will trigger the development of HIT. The estimated frequency of catheter-associated HIT is around $0.4 \%$ [30]. Patients with central catheters and HIT antibodies are at a higher risk for both upper-extremity and lower-extremity DVT occurring at the catheter site [31]. The larger devices (i.e., VAD, ECMO, intra-aortic balloon pump) require high doses of systemic $\mathrm{UFH}$, increasing the risk of seroconversion and clinically apparent HIT. Interestingly, the incidence of HIT in this population is around 8\% [32], while the rate of seroconversion by immunoassay has been reported between 25 and $75 \%$ [15, 32, 33]. Such a wide range depends on the criteria used to define HIT, the populations included, and the difference in confirmatory tests used for diagnosis.

\section{Pathogenesis}

The binding specificity of heparin is determined by its negative charge, molecular size, molecular weight, and chain length [34••]. Heparin binding to the platelet surface can trigger the release of PF4, a positively charged chemokine secreted from the $\alpha$ granules of activated platelets [35]. PF4 readily binds negatively charged proteins on the endothelium and also to soluble proteins such as heparin [36]. Excess PF4 binding can alter the usual configuration of the endothelial proteins, expressing new antigens and inducing an immune response [34••, 37].

To be immunogenic, the PF4-heparin complexes must be soluble and sizable [25] to interact with the Fc $\gamma$ receptors present on platelets and monocytes [38]. As a result of this interaction, these cells are activated and potentiate thrombin generation.

In HIT, high-affinity IgG antibodies are produced soon after heparin exposure along with $\operatorname{IgA}$ and $\operatorname{IgM}$ antibodies [39]. In contrast to other conditions, HIT does not present with an initial IgM phase [40]. This rapid response with IgG might be related to exposure early in life to bacteria or host cells with PF4 bound to surface polyanions [41, 42]. Repeated exposure to heparin does not necessarily lead to recurrent episodes of 
HIT (e.g., non-anamnestic), suggesting that these antibodies disappear within a short time [43-45] due to a lack of a robust increase in memory B-cells $[45,46]$.

The fine balance between molar concentrations of PF4 relative to heparin determines the immune response in HIT. Molar concentrations where one component exceeds the other will promote the formation of complexes that are nonimmunogenic and that will not be favorable for platelet binding $[15,25,42]$. This may explain why seropositive HIT does not necessarily translate to clinically apparent HIT. The immunogenic ultralarge PF4-heparin complexes form in the presence of a 1:1 $\mathrm{M}$ ratio. The optimal concentration of PF4 needed to shift antigenicity to higher levels seems to be related to heparin dosing in the setting of platelet activation (i.e., surgery, trauma, diabetes, inflammation, etc.) [42]. Patients exposed intraoperatively to very high doses of heparin (e.g., cardiovascular surgery and cardiopulmonary bypass), where there is more heparin compared to PF4, are less likely to develop HIT [25]. Conversely, standard postoperative doses (e.g., orthopedic surgery) seem to produce a more favorable PF4/heparin ratio for clinically significant HIT [15].

HIT antibodies can develop even in the absence of heparin exposure, suggesting the presence of a group of B-cells that are triggered by inflammation and lack of immune regulation [47, 48]. Although rare, spontaneous or autoimmune HIT can occur through the binding of PF4 to other major anionic proteins including nucleic acids and bacterial lipopolysaccharides $[41,49]$. Thrombocytopenia from autoimmune HIT may persist for weeks, even after the initiation of an alternative drug for anticoagulation [50].

HIT is characterized by thrombocytopenia or a fall of more than $50 \%$ in the baseline platelet count measured after surgery [11]. Around 85-90\% of the patients diagnosed with HIT present with thrombocytopenia [51]. Thrombocytopenia (or the $50 \%$ fall in the platelet count) classically starts between 4 and 10 days of heparin exposure and more commonly between 6 and 15 days after the first heparin exposure in more than $90 \%$ of the patients with HIT [52]. By several reports, the platelet count reaches nadir values by day 8 and the first evidence of thrombosis usually starts by day 10 . Some patients develop thrombocytopenia earlier (within 2 days of exposure), but those patients have usually been exposed to heparin before, typically within 2-3 weeks, yet sometimes within 100 days before heparin re-exposure $[45,50]$.

Thrombosis is common in HIT patients. It is estimated that around $50 \%$ of patients diagnosed with HIT in the postoperative period will present with thrombotic complications that might be a threat to life and/or limb [2 $\bullet$. Venous thromboembolic disease, such as deep vein thrombosis or pulmonary embolus, is more common than arterial thrombosis (two-fourfold higher), particularly in surgical patients [53]. Patients with vascular disease are an exception as they tend to have similar rates of venous and arterial thrombosis in the setting of
HIT [54]. Arterial thrombosis is also common in cardiac surgery patients [55]. In vascular patients, postoperative HIT is associated with longer hospitalizations, higher cost of stay, and higher rates of non-routine home discharges [56].

Venous thromboembolism (VTE) occurs with a range of incidence between 17 and $55 \%$ in postsurgical cardiac, orthopedic, oncologic, and neurosurgical patients [53, 57]. If HIT goes untreated, then the frequency of thrombosis increases by $6.1 \%$ each day until cessation of heparin and the initiation of alternative anticoagulant therapy [58]. Other manifestations that may present with seropositive HIT include necrotizing skin lesions at heparin injection sites [59, 60], adrenal vein thrombosis with hemorrhagic necrosis [61], cavernous sinus thrombosis [62], acute systemic reactions within $30 \mathrm{~min}$ of an intravenous heparin bolus injection [60], and disseminated intravascular coagulation (DIC) [63-66]. DIC is perhaps the most feared complication if it were to occur along with a HIT diagnosis because clinical manifestations may be similar and the presence of DIC may often suggest HIT has progressed from localized thrombus formation to a systemic thromboinflammatory response [67].

\section{Screening Systems}

Multiple scoring systems can be used for HIT probability estimation. Only the $4 \mathrm{~T}$ score (4Ts) has been validated. The 4Ts comprises four variables evaluated and scored from 0 to 2 (Table 1). The positive (PPV) and negative (NPV) predictive values for this score were assessed in a pooled analysis from 2012 that included approximately 3000 patients. A low score (0-3) has a NPV 0.99 [95\% CI, 0.99-1.00], which essentially rules out HIT. An intermediate score (4-5) has a PPV of 0.48 [95\% CI 0.42-0.55], and a high score (6-8) has a PPV of 0.12 [95\% CI 0.10-0.14]. Intermediate and high scores are not as reliable as only $48 \%$ of the patients with an intermediate score and $12 \%$ of patients with a high score will be accurately diagnosed with HIT with these criteria [6, 17, 68].

The HIT expert probability score (HEP score) was developed according to expert opinion to offer another option for guiding clinical decision making, as previous scores had limited predictive capacities [69]. The score showed good agreement with the serotonin release assay, but greater interobserver variability. However, the predictive values were not different than the 4 Ts' score (positive predictive value of 0.55 (95\% CI $0.25-0.82$ ) and a negative predictive value of 0.97 [95\% CI 0.85-1.00] for a cutoff $>5$ ). This score has not been prospectively validated.

The Lillo-Le Louët model [70] is intended for estimation of the likelihood of HIT in patients following cardiopulmonary bypass $(\mathrm{CPB})$ for cardiac surgery. A low score $(<2)$ suggests a low probability of HIT, while a high score $(\geq 2)$ is associated with a high probability. The negative predictive value of this 
model was comparable with both the HEP and 4 T scores ( $97 \%$ ), but this model has not been prospectively validated.

\section{Differential Diagnosis}

HIT is a challenging diagnosis in the ICU setting. Critically ill patients can often present with thrombocytopenia resulting from diagnoses other than HIT. The timing of thrombocytopenia is tremendously helpful in the diagnosis. The etiology of platelet depletion can be classified as consumptive and destructive (Table 2).

\section{Laboratory Tests}

HIT is a challenging clinical diagnosis as critically ill patients often present thrombocytopenia and are almost ubiquitously exposed to heparin. There are two varieties of laboratory tests for HIT: Immunoassays (ELISA, IgG) and functional assays (serotonin release assay-SRA, heparin-induced platelet activation-HIPA) [85].

Immunoassays detect anti-PF4/H antibodies (platelet-activating and non-activating) and have high sensitivity (>95\%) but low specificity (i.e., high rate of false positives) $[12,15$, 19]. These tests are widely available. Enzyme immunoassays (EIA) identify antibody presence by days $4-5$ reaching maximum reactivity on days 10-12 [40]. These assays use a solid surface with heparin coating to which the patient's plasma is added. Antibody isotypes are measured using a combination of anti-immunoglobulins (Anti-IgG, -IgM, and IgA) or a single isotype (Anti-IgG) [66]. The main limitation of EIAs in HIT is the detection of antibodies that are not necessarily pathogenic (e.g., IgM and IgA antibodies). IgG- focused EIAs seem to be more specific but are likewise limited for identification of clinically relevant HIT antibodies $[2 \cdot, 26]$.

Immunization (presence of $\mathrm{PF} / \mathrm{H}$ antibodies) does not necessarily mean the development of a clinical picture of HIT. In fact, seroconversion (or immunization) occurs frequently without thrombocytopenia or thrombosis [86]. A patient with a low pretest probability of HIT and a positive EIA requires confirmation with a functional assay $[2 \bullet, 87,88 \bullet \bullet$. The goal is to avoid over-diagnosis and over-treatment. A positive EIA does not automatically translate into a HIT diagnosis. Polyclonal immunoassays that detect $\operatorname{IgA}$, IgM, and IgG isotypes can result in false positives for HIT, even when there are no clinical symptoms [89]. It is generally recommended to not pursue said test unless there is a high clinical suspicion of HIT. Treatment based on such results may be unnecessary and potentially harmful [90].

IgG-specific assays are more promising, but cutoffs for optical densities (OD) for HIT have not been clearly defined. OD values are arbitrary units and vary among laboratories 
Table 2 Differential diagnosis for HIT

\begin{tabular}{|c|c|}
\hline Platelet consumption & Platelet destruction \\
\hline Thrombolytics [71] & Drug-induced thrombocytopenia $[72 \bullet \bullet]$ \\
\hline${ }^{\mathrm{a}} \mathrm{GPIIb} / \mathrm{III} a$ antagonists $[71,73,74]$ & Post-transfusion purpura $[72 \bullet \bullet]$ \\
\hline $\operatorname{DIC}[72 \bullet \bullet]$ & Multiorgan failure \\
\hline Sepsis (purpura fulminans) $[72 \bullet \bullet]$ & Paroxysmal nocturnal hemoglobinuria (PNH) [75] \\
\hline${ }^{b}$ Postoperative thrombocytopenic purpura [72••] & Lupus/antiphospholipid syndrome [76] \\
\hline Multiorgan failure & ${ }^{\mathrm{c}}$ COVID-19 [77] \\
\hline \multicolumn{2}{|l|}{ Infective endocarditis $[78,79]$} \\
\hline \multicolumn{2}{|l|}{ Pulmonary embolism [80] } \\
\hline \multicolumn{2}{|l|}{ Liver failure $[81 \bullet \bullet]$} \\
\hline \multicolumn{2}{|l|}{ Diabetic ketoacidosis [82] } \\
\hline \multicolumn{2}{|l|}{ Lupus/antiphospholipid syndrome [76] } \\
\hline \multicolumn{2}{|l|}{ Cancer (mucin-producing adenocarcinomas) [83] } \\
\hline \multicolumn{2}{|l|}{${ }^{\mathrm{c}}$ COVID-19[77] } \\
\hline \multicolumn{2}{|c|}{$\begin{array}{l}\text { a Antibodies that recognize GPIIb/IIIa in the presence of the provoking drug can cross-react with platelet-activat- } \\
\text { ing receptors [74] }\end{array}$} \\
\hline \multicolumn{2}{|c|}{$\begin{array}{l}{ }^{\mathrm{b}} \text { Postoperative thrombotic thrombocytopenic purpura is due to abnormality on the clearance of ultralarge vWF } \\
\text { multimers released from endothelium leads to increased platelet consumption [84] and severe thrombocytopenia } \\
\left(<20 \times 10^{9} / \mathrm{L}\right)[72 \cdot \bullet]\end{array}$} \\
\hline
\end{tabular}

[91]. Strongly reactive ODs (more than 1.0) are usually correlated with clinically apparent HIT $[27,28]$. High ODs are also associated with positive functional assays [27, 28]. It has been suggested that an intermediate or high score on the 4 T's plus a high OD (above 1.0) has a similar accuracy in diagnosing HIT compared with a functional assay, but validation studies are needed [87, $88 \bullet$. An intermediate OD (0.4-1.0) should be confirmed with a functional assay [2•, 87]. HIT assays should be used in the setting of an intermediate-high pretest probability of HIT [88・•]. This level of pretest probability warrants transition to or the initiation of non-heparinoid anticoagulant therapy until serologic data returns (see below for Treatment).

Functional assays (i.e., SRA, HIPA) detect plateletactivating anti-PF4/H antibodies and have high specificity $(80-100 \%)$ [92] but restricted availability due to technical requirements (i.e., require human platelets from known reactive donors, use of radioactive compounds) [92, 93]. SRA only detects antibodies that are capable of activating platelets and can detect antibodies by day 5 after heparin initiation [12]. The proportion of immunized patients who develop HIT is highest among the patients who have a positive SRA [94].

Titers of PF4/H antibodies decrease by 3-4 months [45]. These patients are still at risk for developing rapid-onset HIT on heparin re-exposure during this period unless the functional assays/EIA are negative [87].

\section{Treatment}

HIT treatments aim to reduce thrombin generation, treat any thrombotic events, and interrupt platelet activation triggered by heparin. The mainstay of HIT treatment is the cessation of all forms of heparin and initiation of alternative anticoagulation (Fig. 1). Vitamin K antagonists should be avoided until HIT has resolved and the platelet count has recovered and plateaued. This is due to the increased risk of venous limb gangrene and limb loss with the inhibition of Protein C [2•].

There are options for alternative anticoagulation. Direct thrombin inhibitors (DTI), including argatroban, lepirudin, and bivalirudin, inhibit both free and clot-bound thrombin facilitating the action of antithrombin, preventing the conversion of fibrinogen to fibrin, and preventing the activation of factor XIII [95]. The inhibition is selective and reversible for argatroban and bivalirudin. These drugs have a short half-life (less than $2 \mathrm{~h}$ ) and are monitored by PTT. However, there is a risk for falsely supratherapeutic PTT in the setting of coagulopathy (e.g., DIC, decreased liver function) leading to DTI underdosing [63-65]. DTIs (particularly argatroban) increase INR values and interfere with the protein C pathway [95], so transitioning to warfarin requires specific protocols with an overlap of the two drugs for 5 days to maintain an INR $>4$ $[16 \cdot, 87]$. Argatroban is useful for patients with renal insufficiency due to its hepatobiliary excretion [4] and requires parenteral administration. Lepirudin has to be monitored by 




Fig. 1 Management of heparin-induced thrombocytopenia (HIT) in the intraoperative and the postoperative settings. IVIg intravenous immunoglobulin, $V K A$ vitamin $\mathrm{K}$ antagonists

ecarin clotting time (ECT) during cardiopulmonary bypass and with unexpected bleeding [96].

Bivalirudin is a better option for cardiac surgery as it has a quick onset and short half-life and can be monitored with the activated clotting time (ACT) (Fig. 1). However, bivalirudin carries a risk for excessive bleeding as there is no specific reversal agent available to date. Monitoring its effect can be challenging due to a lack of standardized methods. Currently, ACT or aPTT are used as surrogates of the degree of anticoagulation. For surgeries that require the use of cardiopulmonary bypass, stagnant blood should be avoided at all times due to the increased risk of clotting as bivalirudin is cleaved by thrombin $[97,98]$. Bivalirudin metabolism and clearance can be unpredictable with changes in renal function, core temperature, or repeated doses during a long procedure [99].

Indirect thrombin inhibitors (danaparoid, fondaparinux) work by enhancing the anti-Xa activity of antithrombin III. Danaparoid is not available in the USA since 2002, but it is available in other countries. Fondaparinux has a long half-life $(17 \mathrm{~h})$, requires monitoring with anti-Xa levels, has no effect on INR, and does not interfere with the activation of the protein C pathway [100]. These drugs undergo renal excretion [24, 101] and subcutaneously administered. Both direct and indirect thrombin inhibitors lack a reversal agent.

Platelet transfusions are not indicated in HIT unless the patient has uncontrolled hemorrhage or is undergoing an invasive procedure as it increases the risk of thrombosis [102]. IVC filters are also relatively contraindicated in HIT as there is an increased risk of IVC thrombosis, pulmonary embolism, and limb ischemia [103].

HIT patients with thrombosis or a moderate-high pretest probability should be started on a non-heparin anticoagulant while awaiting the results of confirmatory testing. These patients will require therapeutic anticoagulation for at least 3 months [2•].

\section{Treatment of Isolated HIT (Non-thrombotic)}

Patients with a strong suspicion of isolated HIT or with a confirmed diagnosis should receive therapeutic dose anticoagulation with a non-heparin alternative. The treatment should be continued until platelets recover to a stable plateau [104]. The risk of major bleeding with a DTI for HIT is around $1 \%$ for lepirudin (mean treatment period: 14 days) and 0.6$1 \%$ for argatroban (mean treatment period: 5 days).

\section{Treatment of Patients with a Low Probability of HIT}

Patients with a $4 \mathrm{~T}$ score of equal or less than 3 that do not have a reason for therapeutic dose anticoagulation should continue prophylactic treatment with heparin or an alternative [87]. Patients with an intermediate probability (4Ts score 4 5) without the need for therapeutic anticoagulation should continue prophylactic treatment with a non-heparin alternative.

\section{Adjuvant Treatments}

Intravenous immunoglobulin (IVIg) blocks the platelet Fc $\gamma$ receptors at high doses ( $2 \mathrm{~g} / \mathrm{kg}$ over 2 days) and, consequently, inhibits antibody-mediated platelet activation [105]. It can be an option in patients at high risk for autoimmune HIT or lifethreatening thrombosis and bleeding (e.g., cavernous sinus thrombosis, pregnancy, severe limb ischemia) [106]. IVIG has been used successfully in the preoperative period. It was shown to reduce the activity of HIT antibodies and also decreased the risk of thrombosis while rapidly increasing the platelet count shortly after initiation of therapy [107].

Plasma exchange has been described as an adjunctive therapy for life-threatening HIT, particularly in the setting of urgent cardiac surgery requiring full heparinization. Its mechanism has not been fully determined, but it is thought to remove pathogenic immune complexes and potentially correct coagulopathy with FFP replacement [108]. In cardiac surgery, the 
removal of prothrombotic complexes facilitates heparin use at high doses [16]. A single plasmapheresis session reduces EIA reactivity with a loss of SRA reactivity [109]. The anti-PF4/ heparin antibody titer decreases by approximately $50-80 \%$. In a case series describing 11 cardiac surgery patients with HIT managed with intraoperative plasmapheresis before heparin administration for cardiopulmonary bypass, none of the patients with reduced titers developed clinical HIT [108]. To date, only a few institutions are using plasma exchange for HIT antibody elimination [110].

Intravenous epoprostenol (IV prostacyclin) is a prostaglandin that is FDA-approved as a pulmonary vasodilator for patients with pulmonary arterial hypertension. Intravenous prostacyclins inhibit platelet aggregation by activating intracellular adenylate cyclase to increase cAMP in the platelets. In a small case series, intravenous epoprostenol was administered in an "off-label" manner, in conjunction with heparin, to facilitate anticoagulation during cardiopulmonary bypass [111]. The authors deemed the use of IV epoprostenol to be safe and effective, especially for patients with impaired renal function where bivalirudin-induced anticoagulation may have lingered and been associated with harm after separation from cardiopulmonary bypass. To date, there is a paucity of robust pharmacokinetic/pharmacodynamic studies to further evaluate the use of IV prostacyclins for this indication.

\section{Patients Requiring Surgical Procedures with Heparinization}

In patients with a history of HIT with positive antibodies requiring non-emergent surgical procedures with heparinization (e.g., cardiac and vascular procedures, PCI, etc.), the current recommendation is to delay surgery until the functional assay is negative [112] and then to use heparin [50, 87]. If surgery is urgent or emergent, bivalirudin is the recommended drug of choice [87], although plasmapheresis or therapeutic plasma exchange (TPE) followed by heparin anticoagulation has been safely used at our institution for more than a decade in cardiac surgical operations that require systemic anticoagulation for cardiopulmonary bypass (Fig. 1) [108]. This off-label use of TPE has been supported as a potential option for antibody removal in non-surgical patients [109]. Intraoperative TPE is a valuable adjunct in the management of antibody-mediated syndromes including HIT and is FDA-approved for the treatment of thrombotic thrombocytopenic purpura. TPE permits heparin use by removing immune complexes and HIT antibodies [113]. Intraoperative TPE can also allow for the routine reversal of post-cardiopulmonary bypass heparin reversal using protamine. In a retrospective study of 11 HIT or heparin/PF4 seropositive patients undergoing TPE in preparation for cardiac surgery, a single TPE treatment reduced heparin/PF4 titers by $50-84 \%$, and 7 of 9 patients had normal anti-heparin/PF4 levels after treatment [108]. Following re- exposure to heparin, no serious adverse complications of HIT or to TPE were noted.

\section{Conclusions}

HIT is a devastating clinical condition that will lead to loss of life and/or limb if it is not quickly recognized, diagnosed, and managed in patients that have undergone surgery. The incidence of HIT development is higher in surgical patients than it is in non-surgical patients owing to the inflammatory milieu generated during surgery as well as the potential for heparin exposure, especially in select patients such as those that have undergone orthopedic or cardiac surgery. While the recognition and understanding of the pathogenesis of HIT has dramatically improved over the past several decades due to important basic and translational studies evaluating disease biology, there remains a paucity of information regarding optimal treatment modalities. Current therapy pivots on heparin avoidance and alternative nonheparinoid anticoagulation. Although therapeutic plasma exchange has been used as a means of quickly removing antibodies, comparative effectiveness studies have not been performed to assign a high level of evidence to the use of TPE in the setting of HIT management.

Funding Kamrouz Ghadimi has received research funding from Octapharma, the National Institutes of Health (grant \#T32GM008600), and Duke Health, and has received compensation from UpToDate for service as a consultant.

\section{Compliance with Ethical Standards}

Conflict of Interest Ingrid Moreno-Duarte declares that she has no conflict of interest.

\section{References}

Papers of particular interest, published recently, have been highlighted as:

- Of importance

-• Of major importance

1. Warkentin TE. HIT: lessons learned. Pathophysiol Haemost Thromb. 2006;35(1-2):50-7. https://doi.org/10.1159/000093544.

2. Greinacher A. Clinical practice. Heparin-induced thrombocytopenia. N Engl J Med. 2015;373(3):252-61. https://doi.org/10.1056/ NEJMcp1411910 NEJM case vignette on heparin induced thrombocytopenia that discusses evidence-based guidelines and clinical recommendations for management in 2015.

3. Warkentin TE, Greinacher A. Heparin-induced thrombocytopenia: recognition, treatment, and prevention: the seventh ACCP conference on antithrombotic and thrombolytic therapy. Chest. 2004;126(3 Suppl):311S-37S. https://doi.org/10.1378/chest.126. 3 _suppl.311S. 
4. Napolitano LM, Warkentin TE, Almahameed A, Nasraway SA. Heparin-induced thrombocytopenia in the critical care setting: diagnosis and management. Crit Care Med. 2006;34(12):2898-911. https://doi.org/10.1097/01.CCM.0000248723.18068.90.

5. Wester JP, Haas FJ, Biesma DH, Leusink JA, Veth G. Thrombosis and hemorrhage in heparin-induced thrombocytopenia in seriously ill patients. Intensive Care Med. 2004;30(10):1927-34. https:// doi.org/10.1007/s00134-004-2334-1.

6. Crowther MA, Cook DJ, Albert M, Williamson D, Meade M, Granton J, et al. The 4Ts scoring system for heparin-induced thrombocytopenia in medical-surgical intensive care unit patients. J Crit Care. 2010;25(2):287-93. https://doi.org/10.1016/j.jcrc. 2009.12.006.

7. Selleng S, Malowsky B, Strobel U, Wessel A, Ittermann T, Wollert HG, et al. Early-onset and persisting thrombocytopenia in post-cardiac surgery patients is rarely due to heparin-induced thrombocytopenia, even when antibody tests are positive. J Thromb Haemost. 2010;8(1):30-6. https://doi.org/10.1111/j. 1538-7836.2009.03626.x.

8. Trehel-Tursis V, Louvain-Quintard V, Zarrouki Y, Imbert A, Doubine S, Stephan F. Clinical and biologic features of patients suspected or confirmed to have heparin-induced thrombocytopenia in a cardiothoracic surgical ICU. Chest. 2012;142(4):837-44. https://doi.org/10.1378/chest.11-3074.

9. Warkentin TE, Cook RJ, Marder VJ, Greinacher A. Anti-PF4/ heparin antibody formation postorthopedic surgery thromboprophylaxis: the role of non-drug risk factors and evidence for a stoichiometry-based model of immunization. J Thromb Haemost. 2010;8(3):504-12. https://doi.org/10.1111/j. 1538-7836.2009.03735.x.

10. Warkentin TE, Levine MN, Hirsh J, Horsewood P, Roberts RS, Gent M, et al. Heparin-induced thrombocytopenia in patients treated with low-molecular-weight heparin or unfractionated heparin. N Engl J Med. 1995;332(20):1330-5. https://doi.org/10.1056/ NEJM199505183322003.

11. Warkentin TE, Roberts RS, Hirsh J, Kelton JG. An improved definition of immune heparin-induced thrombocytopenia in postoperative orthopedic patients. Arch Intern Med. 2003;163(20): 2518-24. https://doi.org/10.1001/archinte.163.20.2518.

12. Warkentin TE, Sheppard JA, Moore JC, Moore KM, Sigouin CS, Kelton JG. Laboratory testing for the antibodies that cause heparin-induced thrombocytopenia: how much class do we need? J Lab Clin Med. 2005;146(6):341-6. https://doi.org/10.1016/j.lab. 2005.08.003.

13. Smythe MA, Koerber JM, Mattson JC. The incidence of recognized heparin-induced thrombocytopenia in a large, tertiary care teaching hospital. Chest. 2007;131(6):1644-9. https://doi.org/10. 1378/chest.06-2109.

14. Junqueira DR, Zorzela LM, Perini E. Unfractionated heparin versus low molecular weight heparins for avoiding heparin-induced thrombocytopenia in postoperative patients. Cochrane Database Syst Rev. 2017:4:CD007557. https://doi.org/10.1002/14651858. CD007557.pub3 Cochrane review meta-analysis including three RCTs (1398 participants). Low quality evidence showed that postsurgical patients given LMWH had a lower risk of HIT than those given unfractionated heparin (risk ratio (RR) $0.23,95 \%$ confidence interval (CI) 0.07 to 0.73 ).

15. Warkentin TE, Sheppard JA, Horsewood P, Simpson PJ, Moore JC, Kelton JG. Impact of the patient population on the risk for heparin-induced thrombocytopenia. Blood. 2000;96(5):1703-8.

16. Ivascu NS, Fitzgerald M, Ghadimi K, Patel P, Evans AS, Goeddel LA, et al. Heparin-induced thrombocytopenia: a review for cardiac anesthesiologists and intensivists. J Cardiothorac Vasc Anesth. 2019;33(2):511-20. https://doi.org/10.1053/j.jvca.2018.10.035 Review on diagnosis and management of cardiac surgical patients with heparin induced thrombocytopenia.
17. Pouplard C, Gueret P, Fouassier M, Ternisien C, Trossaert M, Regina S, et al. Prospective evaluation of the "4Ts" score and particle gel immunoassay specific to heparin/PF4 for the diagnosis of heparin-induced thrombocytopenia. J Thromb Haemost. 2007;5(7):1373-9. https://doi.org/10.1111/j.1538-7836.2007. 02524.x.

18. Lubenow N, Hinz P, Thomaschewski S, Lietz T, Vogler M, Ladwig A, et al. The severity of trauma determines the immune response to PF4/heparin and the frequency of heparin-induced thrombocytopenia. Blood. 2010;115(9):1797-803. https://doi. org/10.1182/blood-2009-07-231506.

19. Warkentin TE, Sheppard JA, Sigouin CS, Kohlmann T, Eichler P, Greinacher A. Gender imbalance and risk factor interactions in heparin-induced thrombocytopenia. Blood. 2006;108(9):293741. https://doi.org/10.1182/blood-2005-11-012450.

20. Girolami B, Prandoni P, Stefani PM, Tanduo C, Sabbion P, Eichler $\mathrm{P}$, et al. The incidence of heparin-induced thrombocytopenia in hospitalized medical patients treated with subcutaneous unfractionated heparin: a prospective cohort study. Blood. 2003;101(8):2955-9. https://doi.org/10.1182/blood-2002-072201.

21. Yamamoto S, Koide M, Matsuo M, Suzuki S, Ohtaka M, Saika S, et al. Heparin-induced thrombocytopenia in hemodialysis patients. Am J Kidney Dis. 1996;28(1):82-5. https://doi.org/10.1016/ s0272-6386(96)90134-1.

22. Fausett MB, Vogtlander M, Lee RM, Esplin MS, Branch DW, Rodgers GM, et al. Heparin-induced thrombocytopenia is rare in pregnancy. Am J Obstet Gynecol. 2001;185(1):148-52. https:// doi.org/10.1067/mob.2001.114690.

23. Francis JL, Palmer GJ, Moroose R, Drexler A. Comparison of bovine and porcine heparin in heparin antibody formation after cardiac surgery. Ann Thorac Surg. 2003;75(1):17-22. https:// doi.org/10.1016/s0003-4975(02)04349-7.

24. Warkentin TE, Cook RJ, Marder VJ, Sheppard JA, Moore JC, Eriksson BI, et al. Anti-platelet factor 4/heparin antibodies in orthopedic surgery patients receiving antithrombotic prophylaxis with fondaparinux or enoxaparin. Blood. 2005;106(12):3791-6. https://doi.org/10.1182/blood-2005-05-1938.

25. Rauova L, Poncz M, McKenzie SE, Reilly MP, Arepally G, Weisel JW, et al. Ultralarge complexes of PF4 and heparin are central to the pathogenesis of heparin-induced thrombocytopenia. Blood. 2005;105(1):131-8. https://doi.org/10.1182/blood-200404-1544.

26. Greinacher A, Juhl D, Strobel U, Wessel A, Lubenow N, Selleng $\mathrm{K}$, et al. Heparin-induced thrombocytopenia: a prospective study on the incidence, platelet-activating capacity and clinical significance of antiplatelet factor 4/heparin antibodies of the $\operatorname{IgG}, \mathrm{IgM}$, and IgA classes. J Thromb Haemost. 2007;5(8):1666-73. https:// doi.org/10.1111/j.1538-7836.2007.02617.x.

27. Lo GK, Sigouin CS, Warkentin TE. What is the potential for overdiagnosis of heparin-induced thrombocytopenia? Am J Hematol. 2007;82(12):1037-43. https://doi.org/10.1002/ajh. 21032.

28. Warkentin TE, Sheppard JI, Moore JC, Sigouin CS, Kelton JG. Quantitative interpretation of optical density measurements using PF4-dependent enzyme-immunoassays. J Thromb Haemost. 2008;6(8):1304-12. https://doi.org/10.1111/j.1538-7836.2008. 03025.x.

29. Ling E, Warkentin TE. Intraoperative heparin flushes and subsequent acute heparin-induced thrombocytopenia. Anesthesiology. 1998;89(6):1567-9. https://doi.org/10.1097/00000542199812000-00037.

30. Laster J, Silver D. Heparin-coated catheters and heparin-induced thrombocytopenia. J Vasc Surg. 1988;7(5):667-72. https://doi. org/10.1067/mva.1988.avs0070667. 
31. Hong AP, Cook DJ, Sigouin CS, Warkentin TE. Central venous catheters and upper-extremity deep-vein thrombosis complicating immune heparin-induced thrombocytopenia. Blood. 2003;101(8): 3049-51. https://doi.org/10.1182/blood-2002-05-1448.

32. Koster A, Huebler S, Potapov E, Meyer O, Jurmann M, Weng Y, et al. Impact of heparin-induced thrombocytopenia on outcome in patients with ventricular assist device support: single-institution experience in 358 consecutive patients. Ann Thorac Surg. 2007;83(1):72-6. https://doi.org/10.1016/j.athoracsur.2006.05. 077 .

33. Schroder JN, Daneshmand MA, Villamizar NR, Petersen RP, Blue LJ, Welsby IJ, et al. Heparin-induced thrombocytopenia in left ventricular assist device bridge-to-transplant patients. Ann Thorac Surg. 2007;84(3):841-5; discussion 5-6. https://doi.org/ 10.1016/j.athoracsur.2007.03.049.

34.• Khandelwal S, Arepally GM. Immune pathogenesis of heparininduced thrombocytopenia. Thromb Haemost. 2016;116(5):7928. https://doi.org/10.1160/TH16-01-0074 Summary of investigations related to the pathogenic mechanisms leading to the HIT immune response.

35. O'Brien JR, Etherington MD, Pashley MA. The heparinmobilisable pool of platelet factor 4: a comparison of intravenous and subcutaneous heparin and Kabi heparin fragment 2165 . Thromb Haemost. 1985;54(4):735-8.

36. Visentin GP, Ford SE, Scott JP, Aster RH. Antibodies from patients with heparin-induced thrombocytopenia/thrombosis are specific for platelet factor 4 complexed with heparin or bound to endothelial cells. J Clin Invest. 1994;93(1):81-8. https://doi.org/ 10.1172/JCI116987.

37. Poncz M. Mechanistic basis of heparin-induced thrombocytopenia. Semin Thorac Cardiovasc Surg. 2005;17(1):73-9. https://doi. org/10.1053/j.semtcvs.2004.12.007.

38. Horne MK 3rd, Alkins BR. Platelet binding of IgG from patients with heparin-induced thrombocytopenia. J Lab Clin Med. 1996;127(5):435-42. https://doi.org/10.1016/s0022-2143(96) 90060-8.

39. Warkentin TE, Sheppard JA, Moore JC, Cook RJ, Kelton JG. Studies of the immune response in heparin-induced thrombocytopenia. Blood. 2009;113(20):4963-9. https://doi.org/10.1182/ blood-2008-10-186064.

40. Greinacher A, Kohlmann T, Strobel U, Sheppard JA, Warkentin TE. The temporal profile of the anti-PF4/heparin immune response. Blood. 2009;113(20):4970-6. https://doi.org/10.1182/ blood-2008-08-173062.

41. Krauel K, Potschke C, Weber C, Kessler W, Furll B, Ittermann T, et al. Platelet factor 4 binds to bacteria, [corrected] inducing antibodies cross-reacting with the major antigen in heparin-induced thrombocytopenia. Blood. 2011;117(4):1370-8. https://doi.org/ 10.1182/blood-2010-08-301424.

42. Rauova L, Zhai L, Kowalska MA, Arepally GM, Cines DB, Poncz M. Role of platelet surface PF4 antigenic complexes in heparininduced thrombocytopenia pathogenesis: diagnostic and therapeutic implications. Blood. 2006;107(6):2346-53. https://doi.org/10. 1182/blood-2005-08-3122.

43. Pötschke C, Selleng S, Bröker BM, Greinacher A. Heparininduced thrombocytopenia: further evidence for a unique immune response. Blood. 2012;120(20):4238-45. https://doi.org/10.1182/ blood-2012-04-419424.

44. Greinacher A. Heparin-induced thrombocytopenia. J Thromb Haemost. 2009; 7(Suppl 1):9-12. https://doi.org/10.1111/j.15387836.2009.03385.x.

45. Warkentin TE, Kelton JG. Temporal aspects of heparin-induced thrombocytopenia. N Engl J Med. 2001;344(17):1286-92. https:// doi.org/10.1056/NEJM200104263441704.

46. Lubenow N, Kempf R, Eichner A, Eichler P, Carlsson LE, Greinacher A. Heparin-induced thrombocytopenia: temporal pattern of thrombocytopenia in relation to initial use or reexposure to heparin. Chest. 2002;122(1):37-42. https://doi.org/10.1378/ chest.122.1.37.

47. Krauel K, Schulze A, Jouni R, Hackbarth C, Hietkamp B, Selleng $\mathrm{S}$, et al. Further insights into the anti-PF4/heparin IgM immune response. Thromb Haemost. 2016;115(4):752-61. https://doi.org/ 10.1160/TH15-08-0654

48. Satoh T, Tanaka Y, Okazaki Y, Kaburaki J, Ikeda Y, Kuwana M. Heparin-dependent and -independent anti-platelet factor 4 autoantibodies in patients with systemic lupus erythematosus. Rheumatology (Oxford). 2012;51(9):1721-8. https://doi.org/10. 1093/rheumatology/kes145.

49. Krauel K, Weber C, Brandt S, Zahringer U, Mamat U, Greinacher A, et al. Platelet factor 4 binding to lipid a of gram-negative bacteria exposes PF4/heparin-like epitopes. Blood. 2012;120(16): 3345-52. https://doi.org/10.1182/blood-2012-06-434985.

50. Warkentin TE, Sheppard JA. Serological investigation of patients with a previous history of heparin-induced thrombocytopenia who are reexposed to heparin. Blood. 2014;123(16):2485-93. https:// doi.org/10.1182/blood-2013-10-533083.

51. Warkentin TE. Clinical presentation of heparin-induced thrombocytopenia. Semin Hematol. 1998;35(4 Suppl 5):9-16 discussion 35-6.

52. King DJ, Kelton JG. Heparin-associated thrombocytopenia. Ann Intern Med. 1984;100(4):535-40. https://doi.org/10.7326/00034819-100-4-535.

53. Warkentin TE, Kelton JG. A 14-year study of heparin-induced thrombocytopenia. Am J Med. 1996;101(5):502-7. https://doi. org/10.1016/s0002-9343(96)00258-6.

54. Almeida JI, Coats R, Liem TK, Silver D. Reduced morbidity and mortality rates of the heparin-induced thrombocytopenia syndrome. J Vasc Surg. 1998;27(2):309-14; discussion 15-6. https://doi.org/10.1016/s0741-5214(98)70361-1.

55. Singer RL, Mannion JD, Bauer TL, Armenti FR, Edie RN. Complications from heparin-induced thrombocytopenia in patients undergoing cardiopulmonary bypass. Chest. 1993;104(5): 1436-40. https://doi.org/10.1378/chest.104.5.1436.

56. Subahi A, Osman M, Adegbala O, Abubakar H, Kheiri B, Yassin AS, et al. Clinical and economic burden of heparin-induced thrombocytopenia in hospitalized patients undergoing percutaneous peripheral arterial interventions. Vascular. 2020;28(1):81-6. https://doi.org/10.1177/1708538119868615.

57. Nand S, Wong W, Yuen B, Yetter A, Schmulbach E, Gross FS. Heparin-induced thrombocytopenia with thrombosis: incidence, analysis of risk factors, and clinical outcomes in 108 consecutive patients treated at a single institution. Am J Hematol. 1997;56(1): 12-6. https://doi.org/10.1002/(sici)1096-8652(199709)56:1<12:: aid-ajh3>3.0.co;2-5.

58. Greinacher A, Eichler P, Lubenow N, Kwasny H, Luz M. Heparin-induced thrombocytopenia with thromboembolic complications: meta-analysis of 2 prospective trials to assess the value of parenteral treatment with lepirudin and its therapeutic aPTT range. Blood. 2000;96(3):846-51.

59. Warkentin TE. Heparin-induced skin lesions. Br J Haematol. 1996;92(2):494-7. https://doi.org/10.1046/j.1365-2141.1996. d01-1481.x.

60. Warkentin TE, Roberts RS, Hirsh J, Kelton JG. Heparin-induced skin lesions and other unusual sequelae of the heparin-induced thrombocytopenia syndrome: a nested cohort study. Chest. 2005;127(5):1857-61. https://doi.org/10.1378/chest.127.5.1857.

61. Tan BE. Bilateral adrenal hemorrhage secondary to heparininduced thrombocytopenia. Am J Med. 2020;133:e376-7. https://doi.org/10.1016/j.amjmed.2019.11.027.

62. Meyer-Lindenberg A, Quenzel EM, Bierhoff E, Wolff H, Schindler E, Biniek R. Fatal cerebral venous sinus thrombosis in 
heparin-induced thrombotic thrombocytopenia. Eur Neurol. 1997;37(3):191-2. https://doi.org/10.1159/000117434.

63. Greinacher A, Warkentin TE. The direct thrombin inhibitor hirudin. Thromb Haemost. 2008;99(5):819-29. https://doi.org/10. 1160/TH07-11-0693.

64. Warkentin TE. Heparin-induced thrombocytopenia in critically ill patients. Crit Care Clin. 2011;27(4):805-23, v. https://doi.org/10. 1016/j.ccc.2011.08.001.

65. Warkentin TE. HIT paradigms and paradoxes. J Thromb Haemost. 2011;9(Suppl 1):105-17. https://doi.org/10.1111/j. 1538-7836.2011.04322.x.

66. Linkins LA, Warkentin TE. The approach to heparin-induced thrombocytopenia. Semin Respir Crit Care Med. 2008;29(1):6674. https://doi.org/10.1055/s-2008-1047564.

67. Levy JH, Ghadimi K, Faraoni D, van Diepen S, Levy B, Hotchkiss $\mathrm{R}$, et al. Ischemic limb necrosis in septic shock: what is the role of high-dose vasopressor therapy? J Thromb Haemost. 2019;17(11): 1973-8. https://doi.org/10.1111/jth.14566.

68. Lo GK, Juhl D, Warkentin TE, Sigouin CS, Eichler P, Greinacher A. Evaluation of pretest clinical score (4 T's) for the diagnosis of heparin-induced thrombocytopenia in two clinical settings. J Thromb Haemost. 2006;4(4):759-65. https://doi.org/10.1111/j. 1538-7836.2006.01787.x.

69. Cuker A, Arepally G, Crowther MA, Rice L, Datko F, Hook K, et al. The HIT expert probability (HEP) score: a novel pre-test probability model for heparin-induced thrombocytopenia based on broad expert opinion. J Thromb Haemost. 2010;8(12):264250. https://doi.org/10.1111/j.1538-7836.2010.04059.x.

70. Lillo-Le Louet A, Boutouyrie P, Alhenc-Gelas M, Le Beller C, Gautier I, Aiach M, et al. Diagnostic score for heparin-induced thrombocytopenia after cardiopulmonary bypass. J Thromb Haemost. 2004;2(11):1882-8. https://doi.org/10.1111/j.15387836.2004.00949.x.

71. Harrington RA, Sane DC, Califf RM, Sigmon KN, Abbottsmith $\mathrm{CW}$, Candela RJ, et al. Clinical importance of thrombocytopenia occurring in the hospital phase after administration of thrombolytic therapy for acute myocardial infarction. The thrombolysis and angioplasty in myocardial infarction study group. J Am Coll Cardiol. 1994;23(4):891-8. https://doi.org/10.1016/07351097(94)90634-3.

72.• Skeith L, Baumann Kreuziger L, Crowther MA, Warkentin TE. A practical approach to evaluating postoperative thrombocytopenia. Blood Adv. 2020;4(4):776-83. https://doi.org/10.1182/ bloodadvances.2019001414 Review on work up for differential diagnoses of postoperative thrombocytopenia.

73. Weitz JI, Leslie B, Hudoba M. Thrombin binds to soluble fibrin degradation products where it is protected from inhibition by heparin-antithrombin but susceptible to inactivation by antithrombin-independent inhibitors. Circulation. 1998;97(6): 544-52. https://doi.org/10.1161/01.cir.97.6.544.

74. Bougie DW, Wilker PR, Wuitschick ED, Curtis BR, Malik M, Levine S, et al. Acute thrombocytopenia after treatment with tirofiban or eptifibatide is associated with antibodies specific for ligand-occupied GPIIb/IIIa. Blood. 2002;100(6):2071-6.

75. Wiedmer T, Hall SE, Ortel TL, Kane WH, Rosse WF, Sims PJ. Complement-induced vesiculation and exposure of membrane prothrombinase sites in platelets of paroxysmal nocturnal hemoglobinuria. Blood. 1993;82(4):1192-6.

76. Lipp E, von Felten A, Sax H, Muller D, Berchtold P. Antibodies against platelet glycoproteins and antiphospholipid antibodies in autoimmune thrombocytopenia. Eur J Haematol. 1998;60(5):2838. https://doi.org/10.1111/j.1600-0609.1998.tb01041.x.

77. Connors JM, Levy JH. Thromboinflammation and the hypercoagulability of COVID-19. J Thromb Haemost. 2020;18:1559-61. https://doi.org/10.1111/jth.14849.
78. Arnold DM, Smaill F, Warkentin TE, Christjanson L, Walker I. Cardiobacterium hominis endocarditis associated with very severe thrombocytopenia and platelet autoantibodies. Am J Hematol. 2004;76(4):373-7. https://doi.org/10.1002/ajh.20127.

79. Selleng K, Warkentin TE, Greinacher A, Morris AM, Walker IR, Heggtveit HA, et al. Very severe thrombocytopenia and fragmentation hemolysis mimicking thrombotic thrombocytopenic purpura associated with a giant intracardiac vegetation infected with Staphylococcus epidermidis: role of monocyte procoagulant activity induced by bacterial supernatant. Am J Hematol. 2007;82(8):766-71. https://doi.org/10.1002/ajh.20821.

80. Kitchens CS. Thrombocytopenia due to acute venous thromboembolism and its role in expanding the differential diagnosis of heparin-induced thrombocytopenia. Am J Hematol. 2004;76(1): 69-73. https://doi.org/10.1002/ajh.20009.

81.• Warkentin TE. Heparin-induced thrombocytopenia in critically ill patients. Semin Thromb Hemost. 2015;41(1):49-60. https://doi. org/10.1055/s-0034-1398381 Review on diagnosis, prevention, and management of heparin induced thrombocytopenia in critically ill patients.

82. Sudic D, Razmara M, Forslund M, Ji Q, Hjemdahl P, Li N. High glucose levels enhance platelet activation: involvement of multiple mechanisms. Br J Haematol. 2006;133(3):315-22. https://doi.org/ 10.1111/j.1365-2141.2006.06012.x.

83. Warkentin TE, Elavathil LJ, Hayward CP, Johnston MA, Russett JI, Kelton JG. The pathogenesis of venous limb gangrene associated with heparin-induced thrombocytopenia. Ann Intern Med. 1997;127(9):804-12. https://doi.org/10.7326/0003-4819-127-9199711010-00005.

84. Pavlovsky M, Weinstein R. Thrombotic thrombocytopenic purpura following coronary artery bypass graft surgery: prospective observations of an emerging syndrome. J Clin Apher. 1997;12(4): 159-64. https://doi.org/10.1002/(sici)1098-1101(1997)12: 4<159::aid-jcal>3.0.co;2-9.

85. Francis JL. A critical evaluation of assays for detecting antibodies to the heparin-PF4 complex. Semin Thromb Hemost. 2004;30(3): 359-68. https://doi.org/10.1055/s-2004-831049.

86. Amiral J, Wolf M, Fischer A, Boyer-Neumann C, Vissac A, Meyer D. Pathogenicity of $\operatorname{IgA}$ and/or IgM antibodies to heparin-PF4 complexes in patients with heparin-induced thrombocytopenia. Br J Haematol. 1996;92(4):954-9. https://doi.org/ 10.1046/j.1365-2141.1996.407945.x.

87. Linkins LA, Dans AL, Moores LK, Bona R, Davidson BL, Schulman S, et al. Treatment and prevention of heparin-induced thrombocytopenia: antithrombotic therapy and prevention of thrombosis, 9th ed: American College of Chest Physicians Evidence-Based Clinical Practice Guidelines. Chest. 2012;141(2 Suppl):e495S-530S. https://doi.org/10.1378/chest.11-2303.

88.• Cuker A, Arepally GM, Chong BH, Cines DB, Greinacher A, Gruel Y, et al. American Society of Hematology 2018 guidelines for management of venous thromboembolism: heparin-induced thrombocytopenia. Blood Adv. 2018;2(22):3360-92. https://doi. org/10.1182/bloodadvances.2018024489 Official multidisciplinary guideline from the American Society of Hematology released in 2018 with 33 recommendations for the screening, diagnosis, and treatment of heparin induced thrombocytopenia.

89. Husseinzadeh HD, Gimotty PA, Pishko AM, Buckley M, Warkentin TE, Cuker A. Diagnostic accuracy of IgG-specific versus polyspecific enzyme-linked immunoassays in heparininduced thrombocytopenia: a systematic review and meta-analysis. J Thromb Haemost. 2017;15(6):1203-12. https://doi.org/10. 1111/jth.13692.

90. Harada MY, Hoang DM, Zaw AA, Murry JS, Volod O, Sun BJ, et al. Overtreatment of heparin-induced thrombocytopenia in the 
surgical ICU. Crit Care Med. 2017;45(1):28-34. https://doi.org/ 10.1097/CCM.0000000000002002.

91. Greinacher A, Ittermann T, Bagemuhl J, Althaus K, Furll B, Selleng S, et al. Heparin-induced thrombocytopenia: towards standardization of platelet factor $4 /$ heparin antigen tests. J Thromb Haemost. 2010;8(9):2025-31. https://doi.org/10.1111/j.15387836.2010.03974.x.

92. Greinacher A, Michels I, Kiefel V, Mueller-Eckhardt C. A rapid and sensitive test for diagnosing heparin-associated thrombocytopenia. Thromb Haemost. 1991;66(6):734-6.

93. Warkentin TE, Hayward CP, Smith CA, Kelly PM, Kelton JG. Determinants of donor platelet variability when testing for heparin-induced thrombocytopenia. J Lab Clin Med. 1992;120(3):371-9.

94. Warkentin TE, Arnold DM, Nazi I, Kelton JG. The platelet serotonin-release assay. Am J Hematol. 2015;90(6):564-72. https://doi.org/10.1002/ajh.24006.

95. Di Nisio M, Middeldorp S, Buller HR. Direct thrombin inhibitors. N Engl J Med. 2005;353(10):1028-40. https://doi.org/10.1056/ NEJMra044440.

96. Lubenow N, Eichler P, Lietz T, Greinacher A, Hit Investigators G. Lepirudin in patients with heparin-induced thrombocytopenia results of the third prospective study (HAT-3) and a combined analysis of HAT-1, HAT-2, and HAT-3. J Thromb Haemost. 2005;3(11):2428-36. https://doi.org/10.1111/j.1538-7836.2005. 01623.x.

97. Koster A, Faraoni D, Levy JH. Argatroban and bivalirudin for perioperative anticoagulation in cardiac surgery. Anesthesiology. 2018;128(2):390-400. https://doi.org/10.1097/ALN. 0000000000001976.

98. Dyke CM, Smedira NG, Koster A, Aronson S, McCarthy HL 2nd, Kirshner R, et al. A comparison of bivalirudin to heparin with protamine reversal in patients undergoing cardiac surgery with cardiopulmonary bypass: the evolution -on study. J Thorac Cardiovasc Surg. 2006;131(3):533-9. https://doi.org/10.1016/j. jtcvs.2005.09.057.

99. Koster A, Dyke CM, Aldea G, Smedira NG, McCarthy HL, Aronson S, et al. Bivalirudin during cardiopulmonary bypass in patients with previous or acute heparin-induced thrombocytopenia and heparin antibodies: results of the choose-on trial. Ann Thorac Surg. 2007;83(2):572-7. https://doi.org/10.1016/j.athoracsur. 2006.09.038.

100. Lobo B, Finch C, Howard A, Minhas S. Fondaparinux for the treatment of patients with acute heparin-induced thrombocytopenia. Thromb Haemost. 2008;99(1):208-14. https://doi.org/10. 1160/TH07-04-0252.

101. Pappalardo F, Scandroglio A, Maj G, Zangrillo A, D'Angelo A. Treatment of heparin-induced thrombocytopenia after cardiac surgery: preliminary experience with fondaparinux. J Thorac Cardiovasc Surg. 2010;139(3):790-2. https://doi.org/10.1016/j. jtcvs.2008.11.032.

102. Goel R, Ness PM, Takemoto CM, Krishnamurti L, King KE, Tobian AA. Platelet transfusions in platelet consumptive disorders are associated with arterial thrombosis and in-hospital mortality. Blood. 2015;125(9):1470-6. https://doi.org/10.1182/blood-2014$10-605493$.

103. Nitta N, Shitara S, Nozaki K. Heparin-induced thrombocytopenia in a glioblastoma multiforme patient with inferior vena cava filter placement for deep venous thrombosis. Neurol Med Chir (Tokyo). 2011;51(6):445-8. https://doi.org/10.2176/nmc.51.445.

104. Lewis BE, Wallis DE, Hursting MJ, Levine RL, Leya F. Effects of argatroban therapy, demographic variables, and platelet count on thrombotic risks in heparin-induced thrombocytopenia. Chest. 2006;129(6):1407-16. https://doi.org/10.1378/chest.129.6.1407.

105. Greinacher A, Liebenhoff U, Kiefel V, Presek P, MuellerEckhardt C. Heparin-associated thrombocytopenia: the effects of various intravenous IgG preparations on antibody mediated platelet activation-a possible new indication for high dose i.v. IgG. Thromb Haemost. 1994;71(5):641-5.

106. Tvito A, Bakchoul T, Rowe JM, Greinacher A, Ganzel C. Severe and persistent heparin-induced thrombocytopenia despite fondaparinux treatment. Am J Hematol. 2015;90(7):675-8. https://doi.org/10.1002/ajh.23971.

107. Warkentin TE. High-dose intravenous immunoglobulin for the treatment and prevention of heparin-induced thrombocytopenia: a review. Expert Rev Hematol. 2019;12(8):685-98. https://doi. org/10.1080/17474086.2019.1636645.

108. Welsby IJ, Um J, Milano CA, Ortel TL, Arepally G. Plasmapheresis and heparin reexposure as a management strategy for cardiac surgical patients with heparin-induced thrombocytopenia. Anesth Analg. 2010;110(1):30-5. https://doi.org/10.1213/ ANE.0b013e3181c3c1cd.

109. Warkentin TE, Sheppard JA, Chu FV, Kapoor A, Crowther MA, Gangji A. Plasma exchange to remove HIT antibodies: dissociation between enzyme-immunoassay and platelet activation test reactivities. Blood. 2015;125(1):195-8. https://doi.org/10.1182/ blood-2014-07-590844.

110. Onwuemene OA, Zantek ND, Rollins-Raval MA, Raval JS, Kiss JE, Ipe TS, et al. Therapeutic plasma exchange for management of heparin-induced thrombocytopenia: results of an international practice survey. J Clin Apher. 2019;34(5):545-54. https://doi. org/10.1002/jca.21709.

111. Mertzlufft F, Kuppe H, Koster A. Management of urgent high-risk cardiopulmonary bypass in patients with heparin-induced thrombocytopenia type II and coexisting disorders of renal function: use of heparin and epoprostenol combined with on-line monitoring of platelet function. J Cardiothorac Vasc Anesth. 2000;14(3):304-8.

112. Warkentin TE, Anderson JA. How I treat patients with a history of heparin-induced thrombocytopenia. Blood. 2016;128(3):348-59. https://doi.org/10.1182/blood-2016-01-635003.

113. Kanellopoulou T, Kostelidou T. Literature review of apheresis procedures performed perioperatively in cardiac surgery for ASFA category indications. J Clin Apher. 2018. https://oi.org/ 10.1002/jca.21676.

IMD: None

KG: Consultant for Uptodate ${ }^{\circledR}$ for coagulation and blood management; Receives grant support from NIH T32GM008600 and Duke Health; Previous support from Octapharma ${ }^{\circledR}$

Publisher's Note Springer Nature remains neutral with regard to jurisdictional claims in published maps and institutional affiliations. 